\section{AGENTES COMUNITÁRIOS DE SAÚDE NAS TRAMAS DA REDE: TERRITÓRIOS E HETEROTOPIAS}

\author{
Community Health Agents in Network Plots: Territories and \\ Heterotopias
}

\author{
Agentes Comunitarios de Salud en las Tramas de la Red: \\ Territorios y Heterotopías
}

\section{Agents Communautaires de Santé dans L'entrelacement du Réseau: Territoires et Hétérotopies}

\begin{abstract}
Resumo
$\mathrm{O}$ artigo tem como objetivo considerar que a estratégia de Redes de Atenção à Saúde (RAS), como um fio condutor de práticas na Atenção Básica à Saúde, possibilita articular dimensões que contribuem para problematizar tanto a noção de território como um valor existencial, quanto a questão do espaço como experiência e constituição da subjetividade. Utilizando-se de um referencial pós-estruturalista, pensar em rede possibilita articular estas noções distintas, contribuindo para problematizar tanto a noção de território como um valor existencial quanto a questão do espaço como experiência e constituição da subjetividade. Conclui-se que o modo como se vivencia o território e como se experimentam os espaços pode contribuir com uma forma alternativa de se pensarem a Rede de Atenção à Saúde (RAS) e o Programa Agentes Comunitários de Saúde, seu elemento constitutivo.
\end{abstract}

Palavras-chave: atenção primária; agentes comunitários de saúde; território; subjetividade.

\section{Abstract}

The article aims to consider that the Network for Health Care (RAS) strategy, as a guiding practice in primary health care, enables to joint dimensions that contribute to problematize both the notion of territory as an existential value, as the issue of space as experience and constitution of subjectivity. Using a post-structuralist framework, thinking about network enables to articulate these different notions, contributing to discuss both the notion of territory as an existential value as the question of space as experience and constitution of subjectivity. It is concluded that the way one experiences the territory and how the spaces are experienced can contribute to an alternative way of thinking the Network Health Care (Redes de Atenção à Saúde - RAS) and the Health Community Agents Program, its constitutive element.

Keywords: primary care; community health workers; territory; subjectivity.

\section{Resumen}

El artículo tiene por objetivo considerar que las estrategias de Red de Atención a la Salud (RAS), como un hilo conductor de prácticas en la Atención Básica en la Salud, posibilita articular dimensiones que contribuyan para problematizar tanto la noción de territorio como un valor existencial, cuanto la cuestión del espacio como experiencia y constitución de la subjetividad. Utilizando un referencial post-estructuralista, pensar en red posibilita articular
Relato de Experiência
1) Mestre em Psicologia pela Universidade Católica Dom Bosco (UCDB). Docente do Curso de Graduação em Psicologia da Universidade Federal de Mato Grosso do Sul.

2) Doutora em Psicologia pela Pontifícia Universidade Católica do Rio Grande do Sul. Psicóloga. Docente e Pesquisadora do Programa de Pós-graduação em Psicologia da Universidade Católica Dom Bosco. Pesquisadora do CNPq bolsista produtividade.

2) Mestre em Psicologia da Saúde pela Universidade Católica Dom Bosco (UCDB). Psicóloga. 
estas distintas nociones, contribuyendo para problematizar tanto la noción de territorio como un valor existencial cuanto la cuestión del espacio como experiencia y constitución de la subjetividad. Se concluye que el modo cómo se vivencia el territorio y cómo se experimentan los espacios puede contribuir para una forma alternativa de pensar acerca de la Red de Atención a la Salud (RAS) y el Programa Agentes Comunitarios de Salud, su elemento constitutivo.

Palabras clave: atención primaria; agentes comunitarios de salud; territorio; subjetividad.

\section{Résumé}

Cet article a le but de considérer que la stratégie des Réseaux d'Attention à la Santé (RAS), comme un fil conducteur des practiques dans l'Attention de Base à la Santé, possibilite articuler des dimensions qui contribuent à la notion de territoire comme valeur existencielle quant à l'espace comme l'éxpérience et constitution de la subjectivité. D'après les références de la pensée post-structuraliste, penser au réseaux possibilite articuler ces notions distinctes, en contribuant à la problématisation de la notion de territoire comme une valeur existentielle et aussi à la qustion de l'espace comme expérience et constitution de la subjectivité. On conclut que la manière de vivre et d'épreuver les espaces font partie d'une façon altérnative de repenser le Réseau d'Attention à la Santé (RAS) et le Programme Agents Communautaires de Santé, son élément constituant.

Most-clés: attention primaire; agents communautaires de santé; territoire; subjectivité.

Este artigo é fruto de discussões que emergem da prática de supervisão de estágio em Psicologia na Atenção Básica à Saúde, voltada para o Programa de Agentes Comunitários de Saúde. As reflexões foram constituídas a partir das cenas com as quais o cotidiano de estágio se deparava. Os textos e documentos utilizados na análise são aqueles que foram tomados como suportes teóricos e direcionamentos das políticas públicas para as supervisões. Com base nas supervisões e nas discussões, foi construído este estudo teórico como ferramenta de reflexão sobre as contribuições da psicologia social para o campo das políticas públicas de saúde.

Com base nas práticas desenvolvidas pelo estágio, a finalidade do texto é contribuir para a reflexão sobre o trabalho na saúde focalizando as Redes de Atenção à Saúde (RAS) como estratégia para o Programa Agentes Comunitários de Saúde, a partir das noções de território e de espaços heterotópicos. Além dessa contribuição, considerase também que o Programa de Agentes Comunitários de Saúde (PACS) como elemento constitutivo da RAS pode ser favorecido por análises que problematizem suas práticas de atuação mediante a perspectiva das redes.

Instituída pela Portaria GM no 4.279 de dezembro de 2010, a Rede de Atenção à Saúde (RAS) emerge como mais um dispositivo de fortalecimento da integralidade, equidade e universalidade, princípios fundamentais do Sistema Único de Saúde (MS, 2010). Não apenas no âmbito da saúde, o pensamento em rede constitui uma noção que vem ganhando ampla repercussão nos mais diversos campos de conhecimento. Segundo Parente (2013), a busca pelas essências vem sendo substituída gradativamente pela perspectiva das redes, compreendendo a realidade como múltiplas conexões heterogêneas, constituídas a partir das relações de poder, de saber e de modos de subjetivação.

O campo epistemológico no qual se situam estas análises ancora-se nos estudos pós-estruturalistas de Deleuze e Guattari $(1976,1995)$ e de Foucault (2013). Como ferramentas conceituais, tomam-se, primeiramente, de Deleuze e Guattari as noções de sistema corte-fluxo e ritornelo para pensar a questão do território. Num segundo momento, a noção de espaço heterotópico é engendrada pelo pensamento foucaultiano, possibilitando analisar os modos de subjetivação por meio da relação com os espaços. É preciso salientar que não se busca sintetizar as noções de território e de heterotopia, já que se trata de conceitos distintos, mas estas são utilizadas para problematizar a questão das redes mediante a posição dos agentes de saúde e seu espaço de atuação.

A partir destas considerações inicias, o artigo tem como objetivo considerar que a estratégia de Redes de Atenção à Saúde (RAS), como um fio condutor de práticas na Atenção Básica à Saúde, possibilita articular dimensões distintas, contribuindo para problematizar tanto a noção de território como um valor existencial, quanto a questão do espaço como experiência e constituição da subjetividade.

\section{Agentes Comunitários de Saúde: Entre Fluxos, Cortes e Desterritorializações}

Na Rede de Atenção à Saúde, o PACS apresenta-se como umas das principais estratégias da atenção primária/ Estratégia de Saúde da Família (MS, 2010). Da perspectiva das redes, a posição ocupada pelo agente comunitário de saúde (ACS) traz importantes implicações sociais a seu território de atuação. Conforme Lemke e Silva (2010), a já consolidada noção de território da atenção básica se ancorou nos trabalhos do geógrafo Milton Santos sobre território-processo, trazida pelos sanitaristas que lutavam pela implantação do SUS. Para Lancetti (2006), esta íntima relação dos ACS com seu território que o constitui como um trabalhador afetivo e possuidor de uma grande potência terapêutica. O Ministério da Saúde (2001) indica as principais atividades dos agentes comunitários de saúde: 
cadastramento/diagnóstico, identificação de microáreas de risco, realização de visitas domiciliares, ações coletivas e ações intersetoriais. Dentre estas, destacam-se as visitas domiciliares que seguem um itinerário visando ao mapeamento do território e das demandas da comunidade onde os agentes atuam.

Proveniente do campo da geografia, o conceito de território, para este trabalho, encontra-se ancorado na filosofia da diferença de Deleuze e Guattari $(1976,1995)$ em contraposição a uma filosofia do mesmo. Conforme esta última, cumprir um itinerário parece implicar tão somente o preenchimento de relatórios e o mapeamento de certo território para torná-lo ainda mais conhecido. Não há, nessa perspectiva, espaço para a diferença: tanto o território quanto as pessoas passam a ser objetos prontos a serem perscrutados. Em contraste, nos estudos de Deleuze e Guattari (1976, 1995), o território que se ocupa vai muito além de um lugar geográfico, de uma região a ser conhecida ou de um espaço acabado: o território possui um valor existencial (Zourabichvili, 2004). A temática do território existencial articulado com a atenção básica é recente, mas já é possível encontrar algumas interessantes discussões no campo da Saúde Coletiva (Lancetti, 2006; Ferreira, 2008; Lemke \& Silva, 2010; Macerata, Soares, \& Ramos, 2014; Piccinini \& Silva, 2015). O trabalho de Merhy (2002) sobre o trabalho vivo em ato que se ancora nos referenciais da cartografia também pode ser aproximado aqui da noção de território existencial. As discussões que se procura traçar pretendem articular a noção de território existencial com a temática da heterotopia foucaultiana objetivando contribuir com os estudos da atenção básica pelo viés da saúde coletiva.

Podemos argumentar que a relação do agente com o território excede o simples cumprimento de itinerários ou mapeamentos de sua região, já que implica constantes encontros e desencontros, um trabalho vivo e relacional (Merhy, 2002): há um fluxo das moradias a visitar, um fluxo de doenças a registrar, um fluxo do transitar pelas ruas, um fluxo do clima, um fluxo no suor dos agentes etc.

Acontece que estes processos se tornariam incompletos se fossem exclusivamente explicados a partir de fluxos, isto porque, para Deleuze e Guattari (1976), não há uma "ontologia dos fluxos", pois os fluxos possuem sua condição de possibilidade a partir do sistema corte-fluxo, apresentado pelo conceito de máquina:

Longe de se opor à continuidade, o corte a condiciona, implica ou define o que ele corta como continuidade ideal. É que, como vimos, toda máquina é máquina de máquina. A máquina só produz um corte de fluxo na medida em que está conectada a outra máquina suposta a produzir o fluxo. E sem dúvida essa outra máquina é, por sua vez, na realidade corte. Mas só o é em relação com uma terceira máquina que produz idealmente, isto é, relativamente, um fluxo contínuo infinito. (Deleuze \& Guattari, 1976, p. 44)

Diferente de uma perspectiva mecanicista, a noção de máquina é subvertida pelos autores como máquina desejante, pois implica a questão do desejo como produção conectada, isto é, os fluxos são produzidos por máquinas e também são cortados por elas (Zourabichvili, 2004). Corte aqui não significa barrar, mas justamente fazer escorrer os fluxos: ora há um corte no fluxo do tempo, dando início ao fluxo de visitas às moradias (máquina-tempo); ora há um corte nas conversas, possibilitando o fluxo dos registros (máquina-enunciação); ora há um corte na visita para que haja um fluxo no transitar para outro domicílio (máquinaburocrática); ora o clima chuvoso corta as visitas para que haja reuniões na Unidade Básica de Saúde (máquinaclimática); ora o clima corta a chuva, possibilitando o fluxo de suor (máquina-corpo) etc.

Esses cortes nunca são uniformes, pois o modo como os fluxos escorrem depende do modo como à incisão é realizada (Zourabichvili, 2004). Isso lembra que os cortes podem ser de diversas naturezas. Algumas situações da máquina produzindo cortes e desencadeando fluxos seriam os constantes rasgos na rotina que tendem a provocar fluxos imprevistos: como o agente lida com uma crise de esquizofrenia? Cortes profundos possibilitariam fluxos mais intensos: como se tornam as visitas do agente após um caso recente de suicídio em sua microárea? Cortes superficiais dão condição para um fluir mais brando e às vezes imperceptível: uma chuva fraca pode atrasar um pouco o percurso a ser seguido ou apenas atrapalhar as visitas.

Conforme Zourabichvili (2004), posteriormente os autores da Filosofia da Diferença aperfeiçoaram o conceito de máquina desejante pelo de agenciamento a partir de dois eixos constitutivos: Num eixo horizontal, agenciamento implica tanto um agenciamento maquínico dos corpos quanto um agenciamento coletivo de enunciação, conteúdo e expressão, respectivamente. Num eixo vertical, encontramse os lados territorializados ou reterritorializados que buscam estabilizar as pontas de desterritorialização (Zourabichvili, 2004). Dito de outro modo: enquanto a territorialização implica linhas de maior estabilidade (como as rotinas diárias), a desterritorialização constitui-se de linhas de fuga (como os imprevistos que abalam as rotinas). Essas linhas desterritorializadas seriam as pontas soltas que possibilitam ou não reterritorialização (possibilitam ou não outras rotinas). Em suma, o trabalho vivo em ato possibilita aos agentes inúmeros processos de territorialização, reterritorialização e desterritorialização, constituindo uma multiplicidade de territórios existenciais (Lancetti, 2006; Lemke \& Silva, 2010; Piccinini \& Silva, 2015).

Sempre em vias de desterritorialização, percorrer um determinado território é, portanto, transitar por processos de diferença e repetição. Para compreender esse processo, 
Deleuze e Guattari (1995) fazem uso da noção de ritornelo. Marcação musical utilizada para simbolizar o retorno de um trecho durante a música, os autores associam a noção de ritornelo ao eterno retorno nietzschiano, procurando dar conta da multiplicidade de processos de saída e de retorno que marcam os cortes-fluxos contínuos. Nessa perspectiva, nunca há um retorno ao mesmo, mas um retorno à diferença: até num dia comum, o agente nunca volta o mesmo de quando saiu. O ritornelo articula-se, assim, com a noção de máquina social que corta e faz fluir, implicando diretamente as relações afetivas do agente com o território.

A partir de uma perspectiva ancorada numa Filosofia da Diferença, a rotina seria uma espécie de ilusão provocada pela estabilização dos múltiplos jogos de forças ao redor das pessoas:

A delimitação formal dos objetos do mundo resulta da lentificação e da redundância que a configuração das forças assume num momento dado. Ou seja, graças à provisória estabilização dos jogos de força somos convencidos da universalidade do mundo a nossa volta. (Escócia \& Tedesco, 2010, p. 94)

Essa estabilização (processos de territorialização) será sempre momentânea, visto que dura até o momento em que é capturada (cortada) e modificada (possibilitando outros fluxos ou outras desterritorializações). Porém, dizer que a rotina é simples ilusão seria menosprezar o peso que esta tem na vida dos ACS. A estabilização provocada pela rotina não marca apenas a duração do tempo como uma percepção apenas "psicológica". A rotina marca diretamente os corpos, marca a carne do agente, já que é em seu corpo que se inscreve sua experiência com o território. Segundo Merhy (2002), no trabalho vivo em ato, o que está em jogo é o uso do corpo, valores e habilidades dos trabalhadores.

Portanto, ao invés de se constituir apenas como um vetor de controle que teria domínio sobre seu caminhar, antes o agente se encontra numa posição de cartógrafo, daquele que experimenta a cada momento cortes e fluxos contínuos. É nesse sentido que os conceitos de máquina (sistema corte-fluxo) e de desterritorialização e ritornelo podem ajudar a compreender a relação dos ACS com seu território de atuação.

Além desses processos de diferença e repetição, dessa experiência com o território, os agentes encontram-se numa posição bastante especial, visto que, ao mesmo tempo em que moram na comunidade, nela são trabalhadores. Lancetti (2006) afirma que a potência radical dos ACS reside justamente nesta posição paradoxal. O conceito de heterotopia pode auxiliar a compreender as experimentações dos espaços.

\section{Programa Agentes Comunitários de Saúde: Heterotopia do Desvio ou Espaço Heterotópico da Saúde?}

Parente (2013, p. 91) afirma que "pensar é pensar em rede". Nesse sentido, além da questão do território, a relação com os espaços constitui um fator importante para se pensarem as tramas da rede na qual os agentes comunitários se encontram. No que se refere à Rede de Atenção à Saúde (RAS), os espaços formam relações horizontais entre diferentes pontos de atenção:

[...] os pontos de atenção passem a ser entendidos como espaços onde são ofertados alguns serviços de saúde, sendo todos igualmente importantes para que sejam cumpridos os objetivos da rede de atenção. Ao contrário da forma de trabalho em sistemas de saúde hierárquicos, de formato piramidal e organizado segundo a complexidade relativa de cada nível de atenção (atenção primária, de média e de alta complexidade), as RAS são espaços que visam assegurar o compromisso com a melhora de saúde da população, ofertando serviços contínuos no âmbito dos diferentes níveis de atenção à saúde. Assim, para a lógica das RAS, um pronto socorro e um centro de especialidades, por exemplo, são igualmente importantes na garantia da atenção à saúde do usuário, pois ambos cumprem papéis específicos para necessidades específicas. (MS, 2010, p.10)

Analisar a relação do agente de saúde com os espaços possibilita compreender que o lugar que o agente ocupa acaba sendo bastante diferente do lugar ocupado por outros moradores. A comunidade onde o agente reside é também o local de sua intervenção; e ele se encontra numa posição duplamente implicada: tanto como trabalhador da saúde quanto como usuário, pois também pode usufruir dos serviços de saúde.

Percorrendo os mais variados espaços (ruas, domicílios, praças, por exemplo), ora como agente comunitário, ora como usuário dos serviços, essa dupla implicação tende a torná-lo um estrangeiro em sua própria terra, um agente paradoxal (Lancetti, 2006). A rua, este espaço dentro-fora, será o território existencial privilegiado de suas andanças (Macerata et al., 2014). Numa conferência realizada junto a arquitetos na Tunísia em 1967, Foucault (2013) chamou de heterotopia a confluência de um espaço real e de um espaço irreal. Diferentemente da utopia, cujo lugar é sempre irreal e imaterial, as heterotopias possuem uma existência material cuja capacidade seria a de refletir, num único espaço, funções múltiplas e até contraditórias.

As moradias constituem um interessante exemplo desse espaço heterotópico pelo fato de que uma característica da heterotopia é a descontinuidade de sua função original. No caso dos agentes, sua relação com os outros residentes em 
seu bairro não será mais a de um morador que somente visita seus vizinhos, mas sua visita (seja em horário de trabalho ou não) tende a tornar-se institucional, na medida em que cada residência é seu espaço de trabalho.

Nessa relação com os espaços, segundo Foucault (2013), uma forma antiga é a heterotopia de crise, cujos lugares estavam reservados para sujeitos em situação crítica: um cômodo de uma casa deixava de ser apenas um quarto quando uma mulher grávida podia ali conceber uma criança. Também não era incomum que o quarto pudesse servir aos últimos momentos de vida a um moribundo. Pode-se dizer que a função da casa não passava de uma essência a outra, mas podia cambiar como um espaço heterotópico ora de vida, ora de morte.

A partir do século XVIII, essas heterotopias de crise foram sendo pouco a pouco substituídas por heterotopias do desvio, em que os espaços eram reservados para todos os desviantes da normalidade (Foucault, 2013). No campo da saúde, uma importante heterotopia do desvio são os hospitais, que passaram a capturar os sujeitos desde o nascimento até a morte: a maternidade tornou-se o lugar apropriado para o nascer, enquanto a unidade de terapia intensiva é espaço para o morrer. Conforme Camargo (2005), a doença e o adoecer não seriam apenas o meiotermo entre esses dois extremos, mas a categoria essencial que passou a fundamentar a racionalidade biomédica. Nesse sentido, a gestação e o falecimento já não são mais crises, mas constituem alguns desvios de uma "saúde normal".

Como uma alternativa ao modelo hospitalocêntrico, emerge, em 1991, o Programa Agentes Comunitários de Saúde, objetivando cumprir com os princípios do Sistema Único de Saúde: equidade, participação popular, integralidade e descentralização (MS, 2001). Contudo, mesmo com enormes avanços, a área da saúde ainda encontra sua maior ancoragem em perspectivas biomedicalizantes, cujo foco, quando não são as doenças em si, é a prevenção destas (Camuri \& Dimenstein, 2010; Ferreira, 2008). Caso os ACS atuem sob essas perspectivas, passam a ser o vetor para espionar todos os que não se conformam "ao dever da boa saúde".

Como, então, escapar dessa moralização das condutas desviantes? A própria noção de heterotopia pode auxiliar:

Se imaginarmos, afinal, que o barco é um pedaço de espaço flutuante, um lugar sem lugar, que vive por si mesmo, que é fechado em si e ao mesmo tempo lançado ao infinito do mar e que, de porto em porto, de escapada em escapada para a terra, de bordel a bordel, chegue até as colônias para procurar o que elas encerram de mais precioso em seus jardins, você compreenderá que o barco foi para a nossa civilização, do século XVI aos nossos dias, ao mesmo tempo não apenas, certamente o maior instrumento de desenvolvimento econômico (não é disso que falo hoje), mas a maior reserva de imaginação. $\mathrm{O}$ navio é a heterotopia por excelência. Em civilizações sem barcos, esgotam-se os sonhos, e a aventura é substituída pela espionagem, os piratas pelas polícias. (Foucault, 2013, pp. 421-422)

Para pensar a heterotopia a partir da imagem do navio, necessita-se ir muito além dos atuais cruzeiros luxuosos, higiênicos e bem administrados. A embarcação pirata seria, então, uma figura mais interessante a essa metáfora (Passetti, 2005). Existentes tanto nas "estórias" (como o Capitão Gancho) quanto na "história" (como os hackers), os piratas seriam aqueles que borram as fronteiras, caminhando entre espaços heterotópicos.

Mas, para associar a figura dos piratas aos agentes comunitários de saúde, é preciso alguns cuidados. Numa sociedade de controle, marcada pela norma, pelo conformismo em seguir protocolos e, portanto, por fazer mais do mesmo, falar sobre pirataria no campo da saúde constitui um grande risco de maus usos do termo. Convém, assim, salientar que, para além do aspecto negativo da ilegalidade que imprime a ideia de pirataria, se objetiva aqui apontar como a capacidade inventiva e a subversão da moral biomedicalizante constituem estratégias fundamentais para não tornar os espaços heterotopias do desvio.

A atitude "pirata" estaria mais para uma postura estratégica de subversão das atitudes de "espionagem" das condutas e do "policiamento" moral. Passetti (2005, p. 12), sobre o anarquista Max Stirner, comenta que "a criança capturada pela moral é como o guerreiro transformado em soldado". No campo da saúde atual, essa metáfora do soldado é bastante pertinente, visto que, mesmo com todas as tentativas de rupturas com o modelo hospitalocêntrico, tais como o Estratégia de Saúde da Família e os Centros de Atenção Psicossocial, é o velho modelo hierárquico que ainda predomina:

Hierarquias delimitadas a partir da prescrição dos saberes, fazeres e poderes constituintes de cada categoria profissional. Equipes que metaforicamente se hierarquizam: tenentes, sargentos, cabos e soldados, isto é: médicos, odontólogos, enfermeiros, técnicos/auxiliares e agentes comunitários de saúde. (Camuri \& Dimenstein, 2010, p. 809)

Se a proposta do Programa Agentes Comunitários de Saúde pretende consolidar os princípios do SUS e escapar de perspectivas preventivistas que possuem como meta o policiamento das doenças, será preciso subverter os modelos hierárquicos. Dito de modo mais direto: para que o campo da saúde deixe de ser espaço da doença e heterotopia do desvio, as práticas de saúde precisam inclinar-se mais para a criatividade "pirata" do que para a espionagem "policial".

Isso porque qualquer trabalhador da saúde que exerça práticas autoritárias atualiza os espaços da saúde como 
heterotopias do desvio. Os efeitos de tal postura são bem conhecidos: discursos hierarquizados entre aquele que sabe e aquele que não sabe; práticas excludentes separando normais dos anormais, enfim, práticas comprometidas com a domesticação dos sujeitos e justificadas pelos dogmas da boa saúde.

É nesse sentido que se defende aqui que o campo da saúde não precisa partir de uma racionalidade biomédica que o entende como um campo de guerra cujos inimigos são as doenças (Camargo, 2005).

A subversão necessária não objetiva partir para o individualismo, deixando de executar atividades que dão certo ou abandonando práticas que competem à categoria dos agentes. Escapar das hierarquizações não significa deixar de atuar na prevenção de doenças, pois implica justamente a invenção de novas formas de preveni-las, para extrapolar, assim, os limites do preventivismo.

Trata-se de enxergar os espaços como possibilidades a novos modos de vida e, portanto, práticas de saúde: as pessoas estão satisfeitas com suas moradias? Há lixeiras suficientes para os resíduos produzidos? Existe no bairro algum campo de futebol para o lazer? As praças estão suficientemente cuidadas? Enfim, é preciso imprimir ao território um valor existencial, ou seja, torná-lo um lugar suficientemente "saudável" para se viver. Dentre estes mais variados espaços, destaca-se aqui a rua: é asfaltada? É segura e iluminada o suficiente? A rua seria uma zona cinzenta, nem dentro nem fora, mas que se constitui como território existencial por excelência da cidade (Macerata et al., 2014).

$\mathrm{O}$ engajamento político do agente, tanto com a comunidade em que atua quanto com sua categoria, também seria uma atitude subversiva em relação às atitudes individualistas, tão comuns nos dias de hoje. Se as moradias são precárias, que ações são possíveis para mudar tal quadro? A qual setor é possível reclamar pela condição das ruas e tratamento de esgoto? Para quem é preciso solicitar a instalação de lixeiras? Quais medidas são necessárias para a construção ou reforma das praças e campos de futebol no bairro? Estas seriam apenas algumas, dentre tantas outras questões, que estão diretamente implicadas com o campo da saúde e, portanto, com o âmbito dos agentes, mas dificilmente será possível tratá-las sem mobilizações coletivas.

A heterotopia como espaço de confluência entre o real e o ideal tem sua condição de possibilidade nas práticas cotidianas, que podem ou não possibilitar outros modos de invenção do presente. Portanto, as práticas em saúde que conseguirem escapar das hierarquizações poderão caminhar por territórios "navegantes", possibilitando criar espaços outros, espaços heterotópicos de saúde.

Esse olhar diferenciado para os espaços pressupõe a construção de outro modo de subjetividade, pois, associada à questão das práticas, se encontra a naturalização da subjetividade dos ACS. Ferreira (2008), em seu estudo sobre a cartografia da subjetividade dos agentes comunitários de saúde, aponta como a delimitação do perfil desse trabalhador se encontra naturalizada a partir de atributos como espírito de liderança, identificação com a comunidade e aptidão para a solidariedade. É claro que tais atributos se apresentam como de suma importância para qualquer profissional da saúde. O grande problema está em conceber a noção de atributos, reduzindo-os a uma essência dos sujeitos, ignorando a complexidade que permeia a constituição da subjetividade (Ferreira, 2008).

Partir do pressuposto de que há "características naturais" para ser agente comunitário torna-se bastante conveniente para práticas institucionalizadas, já que, quando não há "espírito de liderança, identificação com a comunidade ou aptidão para a solidariedade", isso se torna um problema exclusivo do agente, e não da instituição. Ora, o oferecimento de cursos, oficinas e demais capacitações é de responsabilidade da instituição, e é responsabilidade do agente realizá-las. É nesse sentido que a construção de subjetividades se articula de modo direto ao entendimento dos espaços como possuidores de valores existenciais.

\section{Considerações Finais}

Como as relações com o território e com os espaços constituem os mais importantes demarcadores da atividade dos agentes (MS, 2001), o presente trabalho buscou refletir sobre a prática dos ACS em dois momentos. Num primeiro momento, a discussão ancorou-se nos estudos de Deleuze e Guattari (1976, 1995), com uso dos conceitos de sistema corte-fluxo e de ritornelo, problematizando a questão do território. Em seguida, a partir dos estudos de Foucault (2013), buscou-se problematizar a questão do espaço e o modo de subjetividade em que se encontram os agentes, mediante a noção de heterotopia. Mesmo que esses autores sejam contemporâneos e compartilhem certos posicionamentos epistemológicos, a noção de território e de espaço deve ser lida de maneira distinta. Contudo, quando se pensa em rede, tanto a noção de território quanto a de espaço podem auxiliar a compreender a posição complexa na qual o agente comunitário se encontra. Entende-se que o estudo sobre a noção de território e das práticas dos ACS pelo viés pós-estruturalista constitui-se não apenas como mais um trabalho do campo da Saúde Coletiva, mas um compromisso ético-político que se assume ao buscar fortalecer a atenção básica.

Partindo-se das tarefas do agente comunitário de saúde, ao longo deste texto, buscou-se mostrar como sua atuação implica muito mais que mapear uma região já conhecida, pois ele tanto a afeta quanto é afetado por ela. $\mathrm{O}$ território, dessa forma, possui valor existencial quando se entende que o sujeito só existe agenciado e está diretamente 
implicado no modo como o experimenta, tal qual um cartógrafo (Lancetti, 2006). O percorrer dos agentes pode ser compreendido mediante a noção de máquina desejante, que possibilita apresentar a realidade constituída a partir de contínuos e inumeráveis sistemas de cortes e de fluxos. Essa noção pode contribuir para o PACS com a desnaturalização dos espaços, colocando em evidência como o território de atuação pode ser complexo e multifacetado.

As tarefas rotineiras dos agentes podem ser problematizadas pelos conceitos de territorialização, desterritorialização e reterritorialização, assim como pelo de ritornelo, para dar visibilidade a um eterno retorno à diferença. Uma possível contribuição dessas noções seria sua utilização em oficinas de capacitação para trabalhar o modo como os agentes de saúde experienciam suas rotinas.

Como parte das tarefas dos agentes, os espaços percorridos, como as moradias, as unidades básicas de saúde, as praças, dentre outros, quando trabalhados a partir da noção de heterotopia, podem desnaturalizar sua forma de utilização. Nesse sentido, há um risco de os agentes de saúde se tornarem vetores para as heterotopias do desvio, isto é, tornar o campo da saúde uma instância para o policiamento de doenças e posturas hierárquicas. Se o Programa Agente Comunitário de Saúde busca escapar das perspectivas hospitalocêntricas e biomedicalizantes, a espionagem precisará ser subvertida por um agir pirata, a fim de borrar as fronteiras e criar espaços outros de saúde - e é nesse sentido que a capacidade inventiva pode apresentarse como um importante elemento para a Rede de Atenção à Saúde.

\section{Referências}

Camargo Jr., K. R. (2005). A biomedicina. Revista Physis, 15(Supl.), 177-201.

Camuri, D., \& Dimenstein, M. (2010). Processos de trabalho em saúde: Práticas de cuidado em saúde mental na estratégia saúde da família. Saúde e Sociedade, 19(4), 803-813.

Deleuze, G., \& Guattari, F. (1976). O Anti-Édipo. Lisboa: Assírio e Calvim.

Deleuze, G., \& Guattari, F. (1995). Mil platôs: Capitalismo e esquizofrenia (Vol. 4). São Paulo: Editora 34.

Escócia, L., \& Tedesco, S. (2010). O coletivo de forças como plano de experiência cartográfica. In E. Passos, V. Kastrup, \& L. Escóssia (Orgs.), Pistas do método da cartografia: Pesquisa-intervenção e produção de subjetividade (pp. 92-108). Porto Alegre: Sulina.
Ferreira, V. S. C. (2008). Micropolítica do processo de trabalho do agente comunitário de saúde (ACS): Território de produção de cuidado e subjetividade. Tese de Doutorado, Faculdade de Medicina, Universidade Federal do Rio de Janeiro, RJ. Recuperado de http:// www.medicina.ufrj.br/micropolitica/textos/vitoriasolange-ferreira-micropolitica-processo-trabalho-acs. pdf

Foucault, M. (2013). De espaços outros. Estudos Avançados, 27(79), 113-122.

Lancetti, A. (2006). A clínica peripatética. São Paulo: Hucitec.

Lemke, R. A., \& Silva, R. A. N. (2010). A busca ativa como princípio político das práticas de cuidado no território. Estudos e Pesquisas em Psicologia, 10(1), 281-295.

Macerata, I., Soares J. G. N., \& Ramos J. F. C. (2014). Apoio como cuidado de territórios existenciais: Atenção Básica e a rua. Interface, 18(Supl 1), 919-30.

Merhy, E. (2002). Saúde: A cartografia do trabalho vivo. São Paulo: Hucitec.

Ministério da Saúde do Brasil (MS). (2001). Programa agentes comunitários de saúde (PACS). Recuperado de http://bvsms.saude.gov.br/bvs/publicacoes/pacs01.pdf

Ministério da Saúde do Brasil (MS). (2010). Portaria $n^{o}$ 4.279, de 30 de dezembro de 2010. Estabelece diretrizes para a organização da Rede de Atenção à Saúde no âmbito do Sistema Único de Saúde (SUS). Recuperado de http://conselho.saude.gov.br/ultimas_noticias/2011/ img/07_jan_portaria4279_301210.pdf

Parente, A. (2013). Enredando o pensamento: Redes de transformação e subjetividade. In A. Parente (Org.), Tramas da rede (pp. 91-110). Porto Alegre: Sulina.

Passetti, E. (2005). Foucault libertário - heterotopia, anarquismo e pirataria. In Anais do XXIII Simpósio Nacional de História - História: Guerra e Paz. Associação Nacional de História, Londrina: ANPUH. Recuperado de http://anpuh.org/anais/?p=16677

Piccinini, C. A., \& Silva, R. A. N. (2015). A ação dos agentes comunitários de saúde e o trabalho vivo em ato. Trabalho, Educação e Saúde, 13(2), 361-379.

Zourabichvili, F. (2004). O vocabulário de Deleuze. Rio de Janeiro: Relume Dumara. 
Endereço para correspondência:

Jeferson Camargo Taborda

Endereço: Rua José Batista de Camargo, n 760 , Jardim

Redentora. Paranaíba/MS, CEP 79500-000.

E-mail: j.taborda@hotmail.com

Endereço para correspondência:

Anita Guazzelli Bernardes

Endereço: Rua Amazonas, no 1525/62B, Vila Gomes,

Campo Grande/MS, CEP 79022-130.

E-mail: anitabernardes@ig.com.br

Endereço para correspondência:

Camilla Fernandes Marques

Endereço: Rua Mestre Valentim, no 459, Conjunto

Residencial Estrela do Sul, Campo Grande/MS, CEP

79013-320.

E-mail: camilla.fmt@hotmail.com 